\title{
The Impact of Peer Review on EFL Learners' Writing Proficiency: Global and Local Aspects
}

\author{
ElaheH Sotoudehnama \\ Afsaneh Pilehvari \\ Alzahra University
}

Received: 26 June 2014 / Accepted: 10 February 2015

ISSN: $1697-7467$

\begin{abstract}
In response to the theoretical claims considering the beneficial effects of peer review on EFL learners' writing development, this study compares two groups of participants to determine whether the most advantageous effects of peer review can be found in giving or receiving feedback. At two proficiency levels (high vs. low), 122 female EFL learners studying in high-intermediate levels were divided into two groups of givers (participants who only give feedback) and receivers (participants who receive feedback). Three training sessions were held and the results showed that givers improved more significantly than receivers, and almost equally in both global and local aspects of writing, regardless of their proficiency level.

Keywords: peer review, peer editing, global aspects of writing, local aspects of writing, writing proficiency

El impacto de la doble revisión en la destreza escrita de estudiantes de EFL. Aspectos globales y locales

RESUMEN: Este estudio tiene como objetivo comparar dos grupos de participantes para determinar si el efecto beneficioso consiste en dar o recibir comentarios evaluativos. Con este objetivo fueron seleccionados dos grupos en dos niveles diferentes, de 122 estudiantes femeninas y divididas en dos grupos: receptor (participantes que solamente dieron comentarios evaluativos) y evaluador (participantes que solamente recibieron comentarios evaluativos). Se celebraron tres sesiones de entrenamiento/prueba y los datos, sin considerar su nivel de competencia, indicaban que los evaluadores disfrutaban de una habilidad más significativa en la destreza de escritura comparando con los receptores.

Palabras clave: doble revisión, doble edición, aspectos globales de la escritura, aspectos locales de la escritura, competencia en destreza escrita.
\end{abstract}

\section{INTRODUCTION}

It has been a while that having the students get involved in the learning and assessment process has turned into a significant issue in ESL/EFL learning contexts. By encouraging students to participate more actively in various types of activities in the classroom, teachers can hope that the great burden on their shoulders in teacher-centered classrooms can be decreased and as Richards and Renandya (2002:335) point out, the students are given "a better sense of control for their own learning" and become more autonomous and self- sufficient 
learners (Penaflorida, 2002). Students can be encouraged to work hand in hand and certainly under the supervision of their teachers to take advantage of the implementation of peer feedback activities to achieve autonomous learning. Peer review as a nontraditional form of assessment, the role of which has been little explored (Cho \& Cho, 2011), is considered to be a significant component of the feedback and revision process in ESL writing classes (Paulus, 1999). Participating in peer review activities can be a fascinating adventure for students as it enables them to step out of their own selves to see what they have created through the eyes of others (Brown, 2001). Research on ESL peer review has primarily focused on the beneficial effects of this collaborative process on students' learning process (Mangelsdorf \& Schlumberger, 1992).

We can particularly witness the beneficial effects of peer review when the students are meticulously trained to give and use feedback efficiently (Min, 2006). As the students assess their classmates' writings critically, they decide on the strengths and weaknesses of their peers' papers and gradually learn to determine what actually works and what does not; thus, they become aware of the potentially similar mistakes they make in their own writings and their awareness of the crucial elements and rules of fluent and clear writing will be greatly enhanced (Kasper, 1998). According to Rollinson (2005), peer response operates on a more informal and comprehensible level than teacher response. It provides a change from the more one-way interaction between the teacher and the students who have to revise their papers based on the teacher's authoritative comments without necessarily agreeing with or even understanding them.

Nowadays many teachers are also aware of the other benefits of peer review such as creating a potentially high level of interaction between readers and writers (Rollinson, 2005), writing to a real audience (Mangelsdorf, 1992), receiving social support from their peers (Zhang, 1995), participating actively in a wider learning community and taking responsibility for editing their written products (Lam, 2010), and engaging in multiple acts about peers' and their own work (Nicol, Thomson \& Breslin, 2013). Therefore, although it entails a great deal of training, the time and the effort required to alleviate the existing difficulties are worth expending as the considerable benefits of peer review to ESL students cannot be neglected (Tang \& Tithecott, 1999).

As today training effective learners is of great importance and classes are changing from being teacher-centered to student-centered, this study can ultimately help us move toward the goal of training autonomous self-reviewers and independent writers, who can accurately evaluate their own writings, assess different areas which need to be improved (local or global aspects of writing), and revise them. Critical evaluation is a necessary skill and a vital tool in our students' hands which helps them effectively review texts and see the existing logical gaps, problems with organization, and other defects that weaken the argument of paper on a global level (Thompson, 2002). Developing the students' editing skills (the local level) is also necessary as the grammatical inaccuracies can have negative effects on the overall quality of our students' writing (Ferris, 2002).

This study seeks to investigate the impact of peer review on two groups of EFL learners' writing proficiency, the ones who only provide feedback and the ones who only receive it. In fact, it is somehow the replication of Lundstrom and Baker's study (2009) in which they declared that the givers would outperform the receivers and manage to make significant progress. This result seemed surprising to the researchers as it was believed that several criteria 
such as individual differences and teaching effects might have greatly influenced it. Their study was conducted with 91 beginning and intermediate students, speaking eight different native languages. The age, gender, or nationality of the students was not mentioned, the classes were taught by different instructors, and the existing criteria at that English Language Center based on which the learners were divided into beginning and intermediate (high and low proficient) students were accepted as the proficiency differentiation indicator. Hence, the researchers in the current study tried to control these attributes by carefully choosing the participants and determining their language proficiency level by means of a test as will be seen in section 3 below.

\section{RESEARCH QUESTIONS}

Is there any significant difference in the writing ability of givers (the participants who only give feedback) and receivers (the participants who only receive feedback) with different levels of language proficiency (high vs. low)?

In which aspect of writing (the global or the local aspects) does the outperformer group improve more?

\section{Method}

\subsection{Participants}

The participants were 122 female students aged 18 to 30, selected from a pool of Persian-speaking learners of English, studying in high-intermediate levels (1,2, and 3$)$ at the Iran Language Institute (ILI), Tehran, Iran. The writing title of a proficiency test (Sharpe, 2004) was administered to divide the participants into two groups. Those who scored between 0.5 to 2 standard deviations above the mean were considered as the high group and the ones who scored between 0.5 and 2 standard deviations below the mean were considered as the low group. At both writing proficiency levels the participants were further divided into two groups randomly. The first group was the experimental group (givers) including both high and low proficient writers. The second group was the comparison group (receivers), again including high and low proficient writers. All in all, there existed four groups of participants: the High Experimental Group (19 participants), the Low Experimental Group (18 participants), the High Comparison Group (17 participants) and the Low Comparison Group (18 participants).

\subsection{Instrumentation}

\subsubsection{Writing Proficiency Test}

To make the participants of the comparison and the experimental groups homogeneous, two titles from TOEFL tests (Sharpe, 2004) were given to them, one as a pre-test and the 
other one as post-test after holding three rounds of reviewing/revising activities. The students' papers were analytically scored according to the Essay Scoring Rubric presented by Paulus (1999).

\subsubsection{Checklist}

After each of the three training session, an example essay was given to the givers along with a checklist adapted from a structured "peer feedback sheet" developed by Miao, Badger, and Zhen (2006) $)^{1}$ covering the most significant points regarding the content and the organization of an essay, development of ideas, vocabulary, structure, and mechanics.

\subsubsection{Essay Scoring Rubric}

Essay Scoring Rubric designed by Paulus $(1999)^{2}$ was used to assess the pre and post-writing proficiency of the students. The rationale for selecting this scoring guide was that both global (organization/unity, development, cohesion/coherence) and local aspects of writing (vocabulary, structure, mechanics) could be assessed analytically and it provided a holistic, overall final assessment score. It was based on a ten-point scale, and the students' essays were assigned a score from 1 (the lowest) to 10 (the highest) for each of the six features of writing.

These essays were first graded by two raters and the two scores were then averaged. If the raters disagreed by more than two points (out of ten) in any of the six aspects of a given essay, that essay was given to a third rater to grade its disputed aspect(s). The scores given by the third rater were then averaged with whichever of the two sets of scores that was closer to it. This suggestion was made by Paulus (1999) to guarantee the reliability of rating.

\subsection{Procedure}

On the second session, the pre-test was administered and the students' essays were given to the raters to be marked. Subsequently, the students were divided into high and low groups based on the results of the pre-test. Next, three times during the term, the participants received training on peer review. "For peer review to play its proper role in writing instruction, a well-planned implementation process is needed" (Jacobs, Curtis, Braine, \& Huang, 1998:314).

The training sessions for both givers and receivers were almost the same. They were taught about the global and local aspects of writing. They were given some instructions on how to generate ideas in order to develop different parts of a paragraph and a well-written essay, i.e., topic sentence, an introduction paragraph, major and minor support sentences, and the concluding paragraph. The significance of having a clearly relevant and effective content, concrete, logical, and convincing supporting examples, and the appropriate use

\footnotetext{
${ }^{1}$ Permission letter was taken from the publisher of the article.

${ }^{2}$ Permission letter was taken from the publisher of the article.
} 
of transitional devices, referential ties, and logical connectors was emphasized as well. In addition, they were trained to pay their undivided attention to the structure and vocabulary used in their sentences, i.e., verb tenses, verb forms, parts of speech, pronouns, articles, prepositions, conjunctions, and noun endings in order to produce grammatically correct and clear sentences. The appropriate use of mechanical devices was stressed as well. The final section of the training was slightly different. The givers were given instruction on how to review the essays and give feedback and the receivers were trained to use the feedback to revise those essays.

The essays used in the reviewing/revising activities in this study were authentic texts written by eight students in high and low experimental and comparison groups, selected randomly by the researchers to write three 150 -word essays throughout the term. It is worth mentioning that they were excluded from the experiment but took part in the same reviewing/ revising activities. They wrote each essay two sessions before each training session so the researchers would have enough time to select one of the essays for the high and another one for the low group. The training sessions for the givers were held and the selected example essays were given to them along with a "peer feedback sheet". Givers wrote their comments and suggestions for clarifying the vague or perplexing parts in the margins of the example essays and answered a number of questions. They also detected the errors related to the micro-structures of the writing, e.g., verb forms, verb tenses, spelling errors, noun endings, word order, sentence structure, punctuation marks, etc.

On the subsequent sessions, the essays containing the givers' suggestions and comments in the margins were given to the receivers along with the "peer feedback sheet". The papers of the high givers were given to the high receivers and the papers of the low givers were given to the low receivers. Then, the receivers had to analyze the feedback carefully, follow their peers' instructions, rewrite the ambiguous and confusing parts, and turn the example essays to a highly effective, well-designed, and well-developed piece of writing and hand them in on the following session.

After holding three training sessions for the givers and the receivers, the post-test was administered to determine whether the overall quality of the essays improved as a result of the feedback and revision process or not. The results could also show the specific aspects of writing in which the participants had the most improvements.

\section{Results}

To answer the first research question, the normality of distribution of the post-test scores was checked through one-sample K-S test. The results proved the normality for high givers $(\mathrm{z}=.514, \mathrm{p}=.954)$, low givers $(\mathrm{z}=.656, \mathrm{p}=.783)$, high receivers $(\mathrm{z}=.570, \mathrm{p}=$ $.901)$, and low receivers $(\mathrm{z}=.755, \mathrm{p}=.619)$. Table 1 provides the descriptive statistics for post-test scores. 
Table 1. Descriptive Statistics for Post-test Scores of High and Low Givers and Receivers

\begin{tabular}{|l|l|c|c|c|}
\hline level & groups & Mean & Std. Deviation & $\mathrm{N}$ \\
\hline \multirow{3}{*}{ high } & givers & 33.7632 & 7.73047 & 19 \\
\cline { 2 - 5 } & receivers & 26.4706 & 8.18625 & 17 \\
\cline { 2 - 5 } & Total & 30.3194 & 8.66038 & 36 \\
\hline \multirow{3}{*}{ low } & givers & 27.1944 & 7.16638 & 18 \\
\cline { 2 - 5 } & receivers & 21.1667 & 5.90115 & 18 \\
\cline { 2 - 5 } & Total & 24.1806 & 7.15557 & 36 \\
\hline \multirow{3}{*}{ Total } & givers & 30.5676 & 8.07531 & 37 \\
\cline { 2 - 5 } & receivers & 23.7429 & 7.49546 & 35 \\
\cline { 2 - 5 } & Total & 27.2500 & 8.47158 & 72 \\
\hline
\end{tabular}

Then a two-way ANOVA was carried out to investigate the effects of the independent variables (level and group) separately and see if there was a possible interaction between them. Since the Levene's test result was not significant $(p=.492)$, it was assumed that the variances were approximately equal.

Table 2. Results of Tests of Between-Subjects Effects

\begin{tabular}{|l|c|c|c|c|c|c|}
\hline Source & $\begin{array}{c}\text { Type III Sum } \\
\text { of Squares }\end{array}$ & df & Mean Square & F & Sig. & $\begin{array}{c}\text { Partial } \\
\text { Eta } \\
\text { Squared }\end{array}$ \\
\hline $\begin{array}{l}\text { Corrected } \\
\text { Model }\end{array}$ & $1482.511^{\mathrm{a}}$ & 3 & 494.170 & 9.301 & .000 & .291 \\
\hline Intercept & 52985.772 & 1 & 52985.772 & 997.244 & .000 & .936 \\
\hline Level & 633.337 & 1 & 633.337 & 11.920 & .001 & .149 \\
\hline Group & 797.208 & 1 & 797.208 & 15.004 & .000 & .181 \\
\hline $\begin{array}{l}\text { Level } \\
\text { Group }\end{array}$ & 7.188 & 1 & 7.188 & .135 & .714 & .002 \\
\hline Error & 3612.989 & 68 & 53.132 & & & \\
\hline Total & 58560.000 & 72 & & & & \\
\hline $\begin{array}{l}\text { Corrected } \\
\text { Total }\end{array}$ & 5095.500 & 71 & & & & \\
\hline \\
Level= Levels of Language Proficiency Group= Givers and Receivers
\end{tabular}

Table 2 shows that there is a significant difference between participants with different levels of English language proficiency $F(1,68)=11.920, p=.001$. Also the effect size of $\eta^{2}=0.14$ was proved to be large (Cohen 1988, cited in Pallant, 2007).

There is also a significant difference between the two groups of givers and receivers $F(1,68)=15.004, p<0.001$. Furthermore, the effect size for the "group" variable $(0.181)$ is large, too. However, the results do not indicate a statistically significant interaction between 
Elaheh Sotoudehnama And Afsaneh Pilehvari $\quad$ The Impact of Peer Review on EFL learners...

the two factors, $F(1.68)=0.135, p=.714$. Both high and low givers performed better in the post-test than high and low receivers and there was no interaction effect.

To answer the second research question, a paired-samples $t$-test was undertaken to compare the givers' performance on global and local aspects of writing. Table 3 provides the descriptive statistics of gain scores for the local and the global aspects of givers' writings.

Table 3. Descriptive Statistics for Gain Scores of the Local and Global Aspects of Writing

\begin{tabular}{|c|c|c|c|c|c|}
\hline \multicolumn{2}{|c|}{} & Mean & N & $\begin{array}{c}\text { Std. } \\
\text { Deviation }\end{array}$ & $\begin{array}{c}\text { Std. Error } \\
\text { Mean }\end{array}$ \\
\hline \multirow{2}{*}{ givers } & local & 5.8784 & 37 & 3.96058 & .65112 \\
\cline { 2 - 7 } & global & 5.5676 & 37 & 4.00028 & .65764 \\
\hline
\end{tabular}

Table 4 shows whether the difference between the means of givers' local and global scores is significant or not.

Table 4. Results of Paired Samples Test for Gain Scores of the Local and Global Aspects of Writing

\begin{tabular}{|c|c|c|c|c|c|c|c|c|}
\hline & \multicolumn{5}{|c|}{ Paired Differences } & \multirow[b]{3}{*}{$\mathrm{t}$} & \multirow[b]{3}{*}{$\mathrm{df}$} & \multirow{3}{*}{$\begin{array}{l}\text { Sig. } \\
(2- \\
\text { tailed })\end{array}$} \\
\hline & \multirow[b]{2}{*}{ Mean } & \multirow{2}{*}{$\begin{array}{c}\text { Std. } \\
\text { Deviation }\end{array}$} & \multirow{2}{*}{$\begin{array}{l}\text { Std. } \\
\text { Error } \\
\text { Mean } \\
\end{array}$} & \multicolumn{2}{|c|}{$\begin{array}{l}95 \% \text { Confidence } \\
\text { Interval of the } \\
\text { Difference }\end{array}$} & & & \\
\hline & & & & Lower & Upper & & & \\
\hline $\begin{array}{l}\text { Givers } \\
\text { local - } \\
\text { global }\end{array}$ & .31081 & 3.18711 & .52396 & -.75182 & 1.37345 & .593 & 36 & .557 \\
\hline
\end{tabular}

Based on the results, $(\mathrm{t}(36)=0.593, p>.557)$, there was not any significant difference between the means of givers' local and global scores.

\section{Discussion}

The results of the current study regarding the first research question suggest that the students who were trained to review their peers' essays to provide feedback improved their writing abilities more than the ones who used the received feedback to revise those essays. These results surprisingly confirm the obtained results by Lundstrom and Baker (2009), who declare that L2 writing students improve their own writing by transferring the abilities they learn while reviewing peer texts. They consider the act of providing feedback as the most beneficial aspect of peer review and claim that certain skills may not develop when the students are only trained to use feedback. Tsui and Ng (2000), also suggest that the 
students who comment on the writings of their peers benefit more than the ones who read the comments and modify the texts. By being a critical reader of their classmates' writing, our students activate their linguistic competence and learn to examine, evaluate, and assess their own papers critically to identify the areas which need to be improved without being entirely dependent on their teacher's feedback (Rollinson, 2005).

The teachers should acknowledge that the students are not solely the passive recipients of knowledge and feedback provided by their teachers, and they are thoroughly capable of accomplishing the tasks that lead to their educational success. Teachers learn more and more in the course of time by interacting and collaborating with students, correcting their papers, dealing with their errors, and recognizing the areas in which they need more improvement. Therefore, the same results may be obtained by encouraging the students to practice the same activities. Another point worth considering is that the participants in the experimental groups (high and low givers) outperformed the participants in the comparison groups (high and low receivers) regardless of their level of proficiency. One explanation may be that givers regarded themselves as competent readers, able to make use of their acquired knowledge to detect the existing errors in a piece of writing and suggest tips to improve its quality, which contributed a lot to the enhancement of their self-confidence. "Teachers are responsible to sustain self-confidence where it already exists and to build it where it does not" (Brown, 2001:63). By having our students take on new roles, we can eventually help them be more actively involved in their own learning process. The new role bestowed upon the givers made them pursue their goals much more seriously and enthusiastically as they could see that they were actually using their knowledge of English in a fruitful way. Their dedication and desire to provide detailed suggestions encouraged them to go over what they already knew and learn what they did not in order to be precise. The reviewing tasks helped them widen their horizons and taught them to consider a written text from different perspectives.

Van der Pol, Van den Berg, Admiraal, and Simons (2008) relate the significant achievements of the reviewers to the idea that learning effects of providing feedback are accomplished much more simply and by just having the students invest their time and effort in actively constructing content-oriented reactions. On the other hand, the learning effects of receiving feedback highly depend on the quality of the received feedback and the expertise of the ones who provide it. By having the students deal with their peers' writings, they were given a chance to put their own written products into perspective. Consciousness-raising is one of the momentous benefits of peer review which helps the students identify their potential. Tsui and Ng (2000) assert that though the students have similar mistakes in their writings, they are ordinarily able to spot their peers' mistakes but not their own.

One of the other reasons that can explain why reviewers gained better results is their attention to different aspects of writing. They made an effort to pinpoint all the existing types of errors and write their comments in detail to create a comprehensive image of the required changes. In addition, they were asked to avoid using their native language and write their comments only in English. Hence, the mere act of jotting down their recommendations can be taken as good writing practice which might have contributed to their notable performance in post-test. On the other hand, the receivers mostly focused on modifying the content by adding a few more examples and paraphrasing a number of sentences and making surface-level changes.

Although a number of receivers did a great job clarifying the writers' arguments by providing more details and examples, changing certain words, adding or omitting several 
sentences, and even spotting and correcting the errors which might have been left unattended by givers, the rest of the students were mostly reluctant to make radical changes probably due to lack of confidence or knowledge and even the accidental ambiguity and insufficiency of the reviewers' comments. Although the receivers were frequently reassured that they were actually the final decision makers who could decide on the precision and appropriateness of the received comments before creating any changes, it seems that some of them just stuck to the comments provided by their peers without questioning their accuracy and suitability. This may explain why the passive recipients of knowledge do not improve as much as those who are actively involved in their learning process.

The inferior performance of the receivers can be further explained by considering that recognizing the defective forms may be much simpler than replacing them with correct forms and structures. Therefore, it is illogical to expect a target form to be acquired instantly and permanently after it has only been highlighted through feedback. Students need plenty of time to learn how to replace the errors that affect the quality of a text with the correct forms. Hyland and Hyland (2006) remark that although receiving indirect feedback which involves underlining, circling, or coding errors seems to help the students develop their writing ability more over time and result in long-term improvement, the learners (especially less proficient ones) who are required to revise the essays according to the received feedback, need more explicit explanations to create the necessary changes. Guenette (2007) also insists that teachers should remember that second language acquisition is a gradual and difficult process and the success or failure of giving corrective feedback depends on many known and unknown factors; hence, time is needed so that corrective feedback can contribute to success.

Although low givers obtained higher gain scores, the difference between high givers and low givers' gain scores was not significant, and it seems that both high and low proficient students benefitted from the reviewing activities. Neither the students in the high group, nor the ones in the low group had any experience in providing written feedback and taking part in reviewing activities prior to this experiment; therefore, they both benefitted from whatever they learnt. In addition, by selecting different texts for high and low groups to control the difficulty level of the tasks, they had the opportunity to review the essays written at their own level of writing proficiency. However, the superior performance of the low giver group cannot be ignored. It seems that the participants in the low giver group fully grasped the significance of what they were expected to do and absorbed a great deal of whatever was taught in the training courses like a dry sponge. Their remarkable progress can be attributed to the fact that they had more room for improvement. Lundstrom and Baker (2009) also found that the lower giver group would make the greatest gains and claimed that the language skills of the students at the beginning level were less developed and any guidelines and instructions that helped them create a well-written essay were of great value and enhanced their writing skill drastically.

Conversely, the results of this study contradict with those of Kamimura (2006) who announces that the peer review activities are more advantageous to high proficient participants who exhibit greater improvements in the overall quality of their writings as their higher English proficiency level enables them to internalize and use their newly-obtained knowledge during training and peer review sessions.

Regarding the second research question, it was concluded that although the participants scored differently in local and global aspects of writing, the difference was not significant. 
Providing written instead of oral feedback gave the givers the opportunity to take their time to express their ideas and impressions of a piece of writing, focus their attention to different aspects as they desire, spot the existing errors that impede the comprehension of the readers, and find an appropriate way to write down their suggestions for further improvement to turn it to an almost impeccable piece of writing with the subsequent contribution of the receivers.

The researchers tried to minimize the pressure on the participants by supplying them with a peer feedback sheet to help them understand what they were actually required to do and what kinds of comments they were supposed to make. It also reminded them of the numerous details they had to consider while reviewing the example essays. Jacobs (1987) contends that some students feel reluctant and unwilling to comment on their peers' essays as they believe that they are so homogeneous in knowledge of writing that they cannot actually help each other. In order to deal with these feelings, the tasks must be clearly defined for the students to look more achievable. Furthermore, Min (2008, p: 302) asserts that "The peer feedback sheets alert novice reviewers to audience, purpose, idea, organization, and language use in the text."

The reviewed example essays during the first round of reviewing/revising tasks show that nearly $60 \%$ of the students were incapable of providing feedback concerning the global aspects of writing and they only detected almost half of the errors related to the sentencelevel or local aspects. They did not answer the questions presented in the peer feedback sheet although it provided a lengthy and detailed description of what they had to look for. Their poor performance in the first round of reviewing activities can be due to their lack of confidence, experience, and the skills required to perform these tasks.

As Berg (1999) suggests, students must be given the chance and the opportunity to learn how to read and respond to someone else's writing effectively. While the majority of the givers' revisions concentrated on offering suggestions on the local or surface-level aspects of the essays at the beginning, the students' skills in using the peer feedback sheet and providing well-organized feedback as well as the number of the comments on both aspects especially on global level increased dramatically after holding the second and the third training sessions during which the instructor emphasized the significance of interacting constructively by generating more specific comments and making more meaning revision instead of just focusing on sentence-level aspects.

The observations made in this study were in accordance with the findings of Paulus (1999) who declares that the most common types of changes the students made to their essays were local changes (63\%). Conrad and Goldstein (1999) also admit that the students revised less successfully whenever they had to deal with the problems of logic and argument. However, the participants in Min's (2006) study were more concerned with the coherence of the text and made an effort to improve the texture of the essays and clarify it which might have been due to the instructor's more emphasis on meaning.

We should remember that the essays written by a number of high-intermediate students were used instead of the participants' own writings in the rounds of reviewing/revising tasks for it was supposed to keep the context of experiment as close as possible to that of Lundstrom and Baker's (2009) while removing the shortcomings. As Lundstrom and Baker (2009:33) suggest, "This way we can control the differences in student writing since with

\section{4}


Elaheh Sotoudehnama And Afsaneh Pilehvari $\quad$ The Impact of Peer Review on EFL learners...

different papers there would be the possibility of wide differences in both how well the papers were written and what types of changes were needed." Although certain students might value the importance of seeing the reaction of their peers to their own writing, many students appreciate the anonymity of the papers. The givers could review the papers more critically and honestly, without having to sugar coat their negative comments. By using anonymous papers to be reviewed and revised, no hostility, sarcasm, over-criticism, or unkind comments was observed and the receivers did not become defensive and uncomfortable, for it was not their own work that was criticized by their peers (Hansen and Liu, 2005). Consequently, care must be taken in implementing reviewing/revising activities whenever the students' actual essays are going to be used in language classrooms, as receiving too many negative comments can be extremely discouraging to some students and lead to the creation of unfavorable attitudes toward peer feedback.

\section{Conclusion}

The findings of this study support the general assertion that although peer feedback cannot be considered as a replacement for teacher feedback, it is a significant complementary source of feedback in EFL writing classrooms (Jacobs et al., 1998; Miao et al., 2006; Tsui $\& \mathrm{Ng}, 2000$; Tuzi, 2004). By activating the students' linguistic knowledge and encouraging them to see themselves as genuine and competent readers, they used their acquired reviewing skills to provide meaningful feedback.

The findings of this study offer teachers and researchers who are willing to use peer review as an integral part of their process-oriented writing classrooms reassuring evidence that high-intermediate students have the required knowledge and potential to be successful peer reviewers if they are properly oriented and well-equipped with suitable training. Training helps our students become effective reviewers and draws their attention to the areas they have to be concerned about. It is suggested that all peer review activities take place under the teacher's constant supervision and guidance, "whom ESL learners value as an authority who knows what good writing is" (Guardado \& Shi, 2007:458). Students must be aware of the fact that learning a foreign language, with the various skills involved in it, is not an individual activity. We all learn better by collaborating with our teacher and even our classmates, as sources of knowledge. Peer review creates the necessary context that facilitates this collaboration and results in successful learning.

By taking part in reviewing/revising activities, the students learn that the readership of their writing does not solely belong to the teacher and they are also capable of recognizing the weak as well as the strong points of an essay. Building up the students' confidence is an essential component involved in the process of training autonomous learners who know how to turn their flaws into an asset. As Tsui and $\mathrm{Ng}$ (2000) indicate, incorporating peer comments can transform the context of writing classes. By collaborating with other learners, students are given a chance to voice their thoughts, feelings and argumentations, and are eventually able to develop the strategies required to generate ideas, edit, and revise their written products. 


\section{REFERENCES}

Berg, E.C. (1999). "The effects of trained peer response on ESL students' revision types and writing quality", in Journal of Second Language Writing, 8, 3: 215- 41.

Brown, H.D. (2001). "Teaching by principles: An interactive approach to language pedagogy. $\left(2^{\text {nd }}\right.$ Edition $)$ NY: Longman.

Conrad, S.M. and Goldstein, L.M. (1999). "ESL students' revision after teacher-written comments: Texts, contexts, and individuals", in Journal of Second Language Writing, 8, 2: 147-79.

Cho, Y.H. and Cho, K. (2011). "Peer reviewers learn from giving comments", in Instructional Science, 39, 5: 629-43.

Ferris, D. (2002). "Teaching students to self-edit", in J.C. Richards and W.A. Renandya (eds.), Methodology in Language Teaching: An Anthology of Current Practice. Cambridge: Cambridge University Press, 328-34.

Guardado, M. and Shi, L. (2007). "ESL students' experiences of online peer feedback", in Computers and Composition, 24, 4: 443-61.

Guenette, D. (2007). "Is feedback pedagogically correct? Research design issues in the studies of feedback on writing", in Journal of Second Language Writing, 16, 1: 40-53.

Hansen, J. and Liu, J. (2005). "Guiding principles for effective peer response", in ELT Journal, 59, 1: 31-38.

Hyland, K. and Hyland, F. (2006). "Feedback on second language students' writing", in Language Teaching, 39, 2: 83-101.

Jacobs, G. (1987). "First experiences with peer feedback on compositions: Student and teacher reaction", in System, 15, 3: 325-33.

Jacobs, G.M., Curtis, A., Braine, G. and Huang, S.Y. (1998). "Feedback on students' writing: Taking the middle path", in Journal of Second Language Writing, 7, 3: 307-17.

Kamimura. T. (2006). "Effects of peer review on EFL student writers at different levels of English proficiency: A Japanese context", in TESL Canada Journal, 23, 2: 12-39.

Kasper, L.F. (1998). "ESL writing and the principles of non-judgmental awareness: Rationale and implementations". TETCY 25: 58-66, available from: http://lkasper.tripod.com/esl.pdf, accessed 12 August, 2014.

Lam, R. (2010). "A peer review training workshop: Coaching students to give and evaluate peer feedback", in TESL Canada Journal, 27, 2: 114-27.

Lundstrom, K. and Baker, W. (2009). "To give is better than to receive: The benefits of peer review to the reviewers own writing", in Journal of Second Language Writing, 18, 1: 30-43.

Mangelsdorf, K. (1992). "Peer reviews in the ESL composition classroom: What do the students think?", in ELT Journal, 46, 3: 274-84.

Mangelsdorf, K and Schlumberger, A. (1992). "ESL student response stances in a peer review task", in Journal of Second Language Writing, 1, 3: 235-54.

Miao, Y., Badger, R. and Zhen, Y. (2006). "A comparative study of peer and teacher feedback in a Chinese EFL writing class", in Journal of Second Language Writing, 15, 3: 179-200.

Min, H.T. (2006). "The effects of trained peer review on EFL students' revision types and writing quality", in Journal of Second Language Writing, 15, 2: 118-41.

Min, H.T. (2008). "Reviewer stances and writer perceptions in EFL peer review training", in English for Specific Purposes, 27, 3: 285-305.

Nicol, D., Thomson, A. and Breslin, C. (2013). "Rethinking feedback practices in higher education: a peer review perspective", in Assessment \& Evaluation in Higher Education, 39, 1: 1-21.

Pallant, J. (2007). SPSS Survival Manual: A Step by Step Guide to Data Analysis Using SPSS for Windows ( $3^{\text {rd }}$ ed.). Berkshire: Open University Press. 
Elaheh Sotoudehnama And Afsaneh Pilehvari $\quad$ The Impact of Peer Review on EFL learners...

Paulus, T.M. (1999). "The effects of peer and teacher feedback on student writing", in Journal of Second Language Writing, 8, 3: 265-89.

Penaflorida, A.H. (2002). "Non-traditional forms of assessment and response to student writing: A step toward learner autonomy", in J.C. Richards and W.A. Renandya (eds.), Methodology in Language Teaching: An Anthology of Current Practice. Cambridge: Cambridge University press, 344-53.

Richards, J.C., \& Renandya, W.A. (2002). "Assessment”, in J.C. Richards and W.A. Renandya (eds.), Methodology in Language Teaching: An Anthology of Current Practice. Cambridge: Cambridge University Press, 335-37.

Rollinson, P. (2005). "Using peer feedback in the ESL writing class", in ELT Journal, 59, 1: 23-30.

Sharpe, P.J. (2004). How to Prepare for the TOEFL Test: Test of English as a Foreign Language (11 thed.). New York: Barron's Educational Series.

Tang, G.M. and Tithecott, J. (1999). "Peer response in ESL writing", in TESL Canada Journal, 16, 2: 20-38, available from: http://www.teslcanada journal.ca/index.php/tesl/article/ view/716/547, accessed 12 August, 2014.

Thompson, C. (2002). "Teaching critical thinking in EAP courses in Australia", in TESOL Journal, 11, 4: 15-20.

Tsui, A.B.M. and Ng, M. (2000). "Do secondary L2 writers benefit from peer comments?", in Journal of Second Language Writing, 9, 2: 147-70.

Tuzi, F. (2004). "The impact of e-feedback on the revisions of L2 writers in an academic writing course", in Computers and Composition, 21, 2: 217-35.

Van der Pol, J., Van den Berg, B.A.M., Admiraal, W.F., and Simons, P.R.J. (2008). "The nature, reception, and use of online peer feedback in higher education", in Computers and Education, 51, 4: 1804-17.

Zhang, S. (1995). "Reexamining the affective advantage of peer feedback in the ESL writing class", in Journal of Second Language Writing, 4, 3: 209-22. 